\title{
Cyclosporine A, in Contrast to Rapamycin, Affects the Ability of Dendritic Cells to Induce Immune Tolerance Mechanisms
}

\author{
Maja Machcińska ${ }^{1,3}\left(\right.$ Monika Kotur $^{1} \cdot$ Aleksandra Jankowska ${ }^{1} \cdot$ Marta Maruszewska-Cheruiyot ${ }^{2} \oplus \cdot$ Artur $^{\text {Laski }}{ }^{1}$. \\ Zuzanna Kotkowska $^{1} \cdot K_{\text {Katarzyna Bocian }}^{1}$ (I) - Grażyna Korczak-Kowalska ${ }^{1}$ (])
}

Received: 9 February 2021 / Accepted: 16 July 2021 / Published online: 10 October 2021

(c) The Author(s) 2021

\begin{abstract}
Following organ transplantation, it is essential that immune tolerance is induced in the graft recipient to reduce the risk of rejection and avoid complications associated with the long-term use of immunosuppressive drugs. Immature dendritic cells (DCs) are considered to promote transplant tolerance and may minimize the risk of graft rejection. The aim of the study was to evaluate the effects of immunosuppressive agents: rapamycin (Rapa) and cyclosporine A (CsA) on generation of human tolerogenic DCs (tolDCs) and also to evaluate the ability of these cells to induce mechanisms of immune tolerance. tolDCs were generated in the environment of Rapa or CsA. Next, we evaluated the effects of these agents on surface phenotypes (CD11c, MHC II, CD40, CD80, CD83, CD86, CCR7, TLR2, TLR4), cytokine production (IL-4, IL-6, IL-10, IL-12p70, TGF- $\beta$ ), phagocytic capacity and resistant to lipopolysaccharide activation of these DCs. Moreover, we assessed ability of such tolDCs to induce $\mathrm{T}$ cell activation and apoptosis, Treg differentiation and production of Th1- and Th2-characteristic cytokine profile. Data obtained in this study demonstrate that rapamycin is effective at generating maturation-resistant tolDCs, however, does not change the ability of these cells to induce mechanisms of immune tolerance. In contrast, CsA affects the ability of these cells to induce mechanisms of immune tolerance, but is not efficient at generating maturation-resistant tolDCs.
\end{abstract}

Keywords Dendritic cells $\cdot$ Immune tolerance $\cdot \mathrm{T}$ cells $\cdot$ Immunosuppressive agents $\cdot$ Rapamycin $\cdot$ Cyclosporine A

$\begin{array}{ll}\text { Abbreviations } \\ \text { APC } & \text { Allophycocyanin } \\ \text { CCR } & \text { C-C chemokine receptor } \\ \text { CFSE } & \text { Carboxyfluorescein succinimidyl ester } \\ \text { CsA } & \text { Cyclosporine A } \\ \text { CTLA-4 } & \text { Cytotoxic T-lymphocyte-associated protein } 4 \\ \text { IFN } & \text { Interferon } \\ \text { IL } & \text { Interleukin } \\ \text { DCs } & \text { Dendritic cells } \\ \text { ELISA } & \text { Enzyme-linked immunosorbent assay }\end{array}$

Maja Machcińska

maja.machcinska@wihe.pl

1 Department of Immunology, Institute of Functional Biology and Ecology, Faculty of Biology, University of Warsaw, Warsaw, Poland

2 Laboratory of Parasitology, General Karol Kaczkowski Military Institute of Hygiene and Epidemiology, Warsaw, Poland

3 Present Address: Present address: Laboratory of Parasitology, General Karol Kaczkowski Military Institute of Hygiene and Epidemiology, Warsaw, Poland

$\begin{array}{ll}\text { FITC } & \text { Fluorescein isothiocyanate } \\ \text { FMO } & \text { Fluorescence minus one } \\ \text { GM-CSF } & \begin{array}{l}\text { Granulocyte-macrophage colony-stimulating } \\ \text { factor }\end{array} \\ \text { LPS } & \text { Lipopolysaccharide } \\ \text { MFI } & \text { Mean fluorescence intensity } \\ \text { MHC } & \text { Major histocompatibility complex } \\ \text { MLR } & \text { Mixed lymphocyte reaction } \\ \text { PBMC } & \text { Peripheral blood mononuclear cells } \\ \text { PE } & \text { Phycoerythrin } \\ \text { Rapa } & \text { Rapamycin } \\ \text { TGF } & \text { Transforming growth factor } \\ \text { TLR } & \text { Toll-like receptor } \\ \text { Tregs } & \text { T regulatory cells }\end{array}$

\section{Introduction}

Following organ transplantation, it is essential that immune tolerance is induced in the graft recipient to reduce the risk of rejection and avoid complications associated with the long-term use of immunosuppressive drugs. It is hence 
crucial to develop methods to promote donor-specific tolerance in the recipient. Although existing therapies are focused on effector cells, a great deal of attention is being paid to dendritic cells (DCs), which may promote transplant tolerance (Marín et al. 2016; Svajger et al. 2014).

Owing to their capacity to regulate both the innate and adaptive immune responses, DCs are considered to play crucial roles in directing the alloimmune response towards transplant tolerance or rejection. It is known that immature DCs, also known as tolerogenic DCs (tolDCs), may minimize the risk of graft rejection and promote transplant tolerance (Li and Shi 2015; Sanjana et al. 2017). Transplant tolerance itself comprises a number of distinct mechanisms, such as the induction of $\mathrm{T}$ cell anergy and apoptosis, the induction of $\mathrm{T}$ regulatory cell (Tregs) proliferation and the selective activation of Th2 cells (Horton et al. 2017; Ochando et al. 2020). These properties enable tolDCs to be used as a base for therapeutic strategies to promote organ transplant tolerance (Moreau et al. 2017). An approach combining tolDCs with various immunosuppressive agents can ensure long-term allograft survival or transplant tolerance (Que et al. 2020; Švajger and Rožman 2020; Thomson et al. 2018, 2019).

Two of the most commonly and effectively used immunosuppressive drugs used after organ transplantation are rapamycin (Rapa) and cyclosporine A (CsA) (Enderby and Keller 2015; Moini et al. 2015). For many years, their main targets were thought to be T cells; however, it has recently been found that immunosuppressive agents could also inhibit DC maturation and allostimulatory capacity (Cangemi et al. 2019; Macedo et al. 2012). Not only has this provided a new insight into the immunopharmacology of these substances, but it also offers novel strategies for the manipulation of DCs ex vivo prior to organ transplantation to promote tolerance induction. There is currently a global effort to create cellular therapies using tolDCs and immunosuppressive drugs to improve long-term outcomes in organ transplantation (Marín et al. 2016; Moreau et al. 2017; Thomson et al. 2019); despite this, little is known about the effects of these drugs on human DCs and past studies lack a unified approach to tolDC generation protocols, and there remains a great need for more comprehensive studies. In addition, previous studies have not examined such a broad range of effects exerted by DCs generated in the environment of immunosuppressive drugs (Rapa and CsA) on the activation and function of $\mathrm{T}$ cells.

Considering that the ultimate goal of such research is to transfer tolDC-based therapy from the laboratory to the clinic, it is extremely important not only to generate DCs with stable tolerogenicity, which are resistant to an exogenous maturation stimulus, but also, and perhaps above all, produce tolDCs which are able to induce mechanisms of immune tolerance. Therefore, the present study evaluates the tolerogenic surface phenotype, anti-inflammatory cytokine production, phagocytic capacity and resistance to maturation of monocyte-generated DCs to determine their tolerogenic properties; it also examines their effects on $\mathrm{T}$ cell activation and survival, Treg induction and selective activation of Th2 cells.

\section{Materials and Methods}

\section{Generation of Monocyte-Derived DCs}

Human peripheral blood mononuclear cells (PBMC) were isolated from the fresh buffy coats of 30 healthy donors from Regional Centre for Blood Donation and Treatment in Warsaw, Poland by density gradient centrifugation using Ficoll-Paque (Gradisol L; Aqua Medica, Lodz, Poland). The donors met the requirements of the Regional Blood stations and agreed to provide blood for research purposes.

The monocytes were isolated from PBMC using an EasySep Human CD14 Positive Selection Kit (StemCell Technologies, Seattle, WA, USA) according to the manufacturer's instructions. The purity, determined by flow cytometry (FACSVerse, Becton Dickinson) using CD14-PE monoclonal antibody (clone 61D3; eBioscience, USA) post isolation, was greater than $95 \%$.

For DC differentiation, monocytes were cultured at $1 \times 10^{6} / \mathrm{ml}$ in AIM-V (Gibco/Invitrogen, Breda, Netherlands) culture medium supplemented with $200 \mathrm{U} / \mathrm{ml} \mathrm{rhGM}-\mathrm{CSF}$ (R\&D Systems, USA) and $500 \mathrm{U} / \mathrm{ml}$ rhIL-4 (R\&D Systems) on 24-well plates at $37{ }^{\circ} \mathrm{C}, 5 \% \mathrm{CO}_{2}$ for 5 days (DC, Control DC). To generate immature DCs with tolerogenic properties, $200 \mathrm{ng} / \mathrm{ml} \mathrm{CsA}$ (CsA-DC; Novartis Pharma, Germany) or $20 \mathrm{ng} / \mathrm{ml}$ Rapa (Rapa-DC; Wyeth-Lederle Pharma, UK) was added from the beginning of cultures. Immature DCs were harvested at day 5 and cell viability was determined using trypan blue ( $>96 \%$ for each sample).

\section{Activation of Monocyte-Derived DCs}

To induce maturation, $1-1.5 \times 10^{6} / \mathrm{ml}$ immature DCs, RapaDC and CsA-DC were stimulated with $1 \mu \mathrm{g} / \mathrm{ml}$ lipopolysaccharide (LPS) from E. coli O26:B6 (Sigma-Aldrich, USA). Cells are referred as DC + LPS, Rapa-DC + LPS and CsA-DC + LPS, respectively. Additionally, Control DCs were also activated with LPS, together with $20 \mathrm{ng} / \mathrm{ml}$ Rapa (DC + LPS + Rapa) or $200 \mathrm{ng} / \mathrm{ml} \mathrm{CsA} \mathrm{(DC} \mathrm{+} \mathrm{LPS} \mathrm{+} \mathrm{CsA).}$ Cells were incubated on 24 -well plates for $24 \mathrm{~h}\left(37^{\circ} \mathrm{C}, 5 \%\right.$ $\mathrm{CO}^{2}$ ) and viability was $>97 \%$ for each sample. 


\section{Phenotypic Characterisation by Flow Cytometry}

The immature and mature DCs were subjected to phenotypic characterization by flow cytometry analysis. The following fluorochrome-conjugated monoclonal antibodies were used according to the manufacturers' protocols: CD11c-APC (clone 3.9; eBioscience, USA), CD14-PE (clone 61D3; eBioscience, USA), CD1c-FITC (clone L161; eBioscience, USA), CD40-PE (clone 5C3; BD Pharmingen, USA), CD80-PE (clone 2D10.4; eBioscience, USA), CD86-PECy7 (clone IT2.2; eBioscience, USA), CD83-FITC (clone HB15E; BD Pharmingen, USA), MHC II-eFluor450 (clone L243; eBioscience, USA), CCR7-APC-eFluor780 (clone 3D12; eBioscience), TLR2-FITC (clone TL2.1; eBioscience, USA), TLR4-PE (clone HTA125; eBioscience, USA), CD36-FITC (clone CD38; eBioscience, USA), DEC205-PE (clone MG38; BD Pharmingen, USA).

Briefly, the cells $\left(1 \times 10^{6}\right)$ were resuspended in $100 \mu \mathrm{l}$ Cell Wash (BD Bioscience, USA) and incubated with appropriate monoclonal antibodies for $30 \mathrm{~min}$ in the dark at $4{ }^{\circ} \mathrm{C}$. Following this, the cells were washed twice with Cell Wash and acquired on FACSVerse calibrated daily using BD FACSuite CS\&T Research Beads Kit (BD Bioscience, USA). The results were analyzed using FACSuite software (Becton Dickinson, USA) and Kaluza Analysis Software (Beckman Coulter, USA). Single-stained cells or BD CompBead Plus (BD Bioscience, USA) were used for compensation in all assays. The positive staining and gating strategy were determined by comparison with an unstained control and fluorescence minus one (FMO) control, if applicable. The DC population was identified based on morphological parameters on a forward vs side scatter (FSC-A/SSCA) plot. Cell aggregates were removed from the analysis using FSC-A versus FSC-H parameters. Dendritic cells were defined as $\mathrm{CD} 11 \mathrm{c}^{+}$cells (Fig. 1). In all experiments, at least 100,000 events were analyzed for each sample. The results were shown as the percentage of positively labelled cells and the mean fluorescence intensity (MFI) was calculated by FACSVerse.

\section{Measurements of Cytokine Production}

Supernatants from immature and mature DC cultures were collected and the presence of interleukin (IL)-6, IL-10, IL$12 p 70$, and transforming growth factor (TGF) $\beta$ was analysed. Supernatants collected from MLR at day 5 of culture were analysed for the presence of Th2 cytokines: IL-4, IL-5, IL-10, IL-13 and Th1 cytokines: IL-2, interferon (IFN)- $\gamma$. The concentration of cytokines was quantified using ELISA Ready-Set-Go! assay (eBioscience, USA) according to the manufacturer's instructions. The absorbance was measured at $450 \mathrm{~nm}$ with a microplate autoreader $\mu$ Quant (BioTek) and analyzed using Gen5 Data Analysis Software (BioTek).
Because IL-4 was added to the culture medium to induce the differentiation of monocytes into DCs, its expression in immature and mature DCs was determined by intracellular staining. The cells were incubated on 24-well plates for $4 \mathrm{~h}$ $\left(37{ }^{\circ} \mathrm{C}, 5 \% \mathrm{CO} 2\right)$ in the presence of $3 \mu \mathrm{g} / \mathrm{ml}$ brefeldin $\mathrm{A}$ (eBioscience, USA), and were then washed twice with PBS and stained with Fixable Viability Dye eFluor506 (eBioscience, USA) and CD11c-APC according to the manufacturer's instructions. The cells were then washed with Cell Wash, fixed and permeabilised using Intracellular Fixation and Permeabilization Buffer Set (eBioscience, USA) and incubated for $20 \mathrm{~min}$ at room temperature with IL-4-PE (clone 8D4-8; eBioscience, USA). The cells were then washed and analysed by flow cytometry.

\section{FITC-Dextran Uptake Assay}

Immature DC, Rapa-DC and CsA-DC $\left(1 \times 10^{6}\right)$ were incubated with FITC-dextran (molecular weight: 40,000; Sigma-Aldrich, USA) at the final concentration of $1 \mathrm{mg} / \mathrm{ml}$ for $30 \mathrm{~min}$ at $37^{\circ} \mathrm{C}$ (control plate at $4{ }^{\circ} \mathrm{C}$ ); the mixture was then washed extensively with Cell Wash and subjected to CD11c-APC staining for flow cytometry analysis.

\section{Allogenic Mixed Lymphocyte Reaction}

Allogenic mixed lymphocyte reaction (MLR) cultures were created by culturing $1 \times 10^{6}$ PBMCs, freshly isolated by density gradient, with $1 \times 10^{5}$ DC, Rapa-DC or CsA-DC (10:1 ratio) in $200 \mu \mathrm{l}$ AIM-V culture medium in 96-well, roundbottom plates for 5 days $\left(37{ }^{\circ} \mathrm{C}, 5 \% \mathrm{CO}_{2}\right)$. These mixed cultures are referred as DC:T, Rapa-DC:T and CsA-DC:T, respectively. The DCs were extensively washed after incubation with Rapa or CsA to avoid carry over of immunosuppressive agents to the MLR culture.

\section{Analysis of T Cell Activation}

The T cells were labelled with $5 \mu \mathrm{M}$ carboxyfluorescein succinimidyl ester (CFSE; Sigma-Aldrich, USA) according to the manufacturer's instructions, and then cocultured with DC, Rapa-DC or CsA-DC. After 5 days of coculture, the cells were harvested and labelled with the following fluorochrome-conjugated monoclonal antibodies: CD3-APC (clone: OKT3, eBioscience, USA), CD69-FITC (clone: FN50, eBioscience, USA) and CD25-PE (clone: BC96, BD Pharmingen, USA) to identify $\mathrm{T}$ cells or CD11c-APC and PD-L1-FITC (clone: MIH1, BD Pharmingen, USA) to identify DCs. All procedures were performed according to the manufacturers' protocols. The cells were prepared for flow cytometry analysis and analysed as described above. 
A
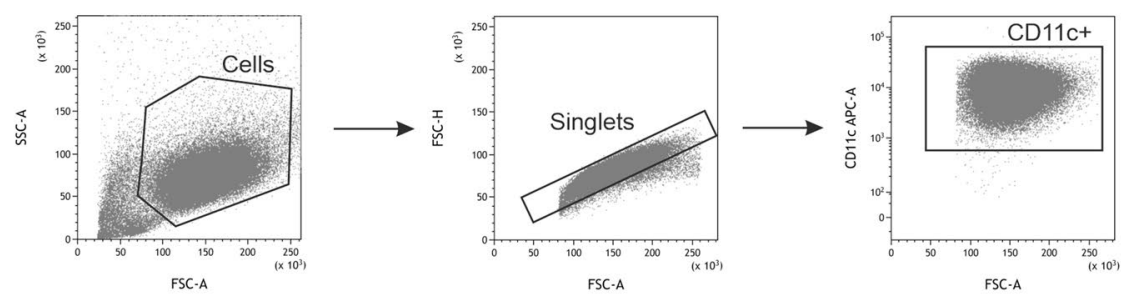

B

MHC II

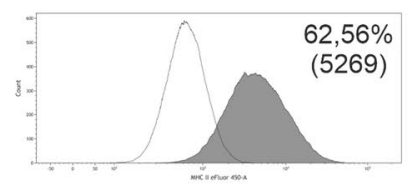

DC

Rapa-DC

CsA-DC

CD80

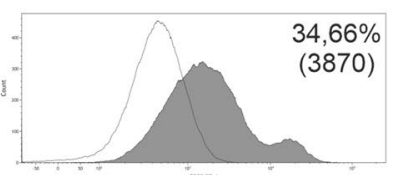

cosent

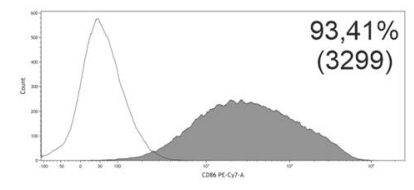

$93,41 \%$
$(3299)$

CD86

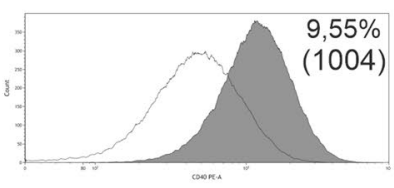

$(1004)$

CD40

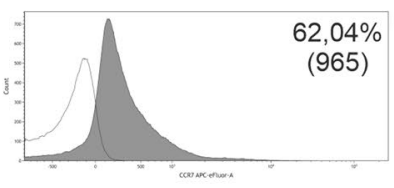

965)

CCR7
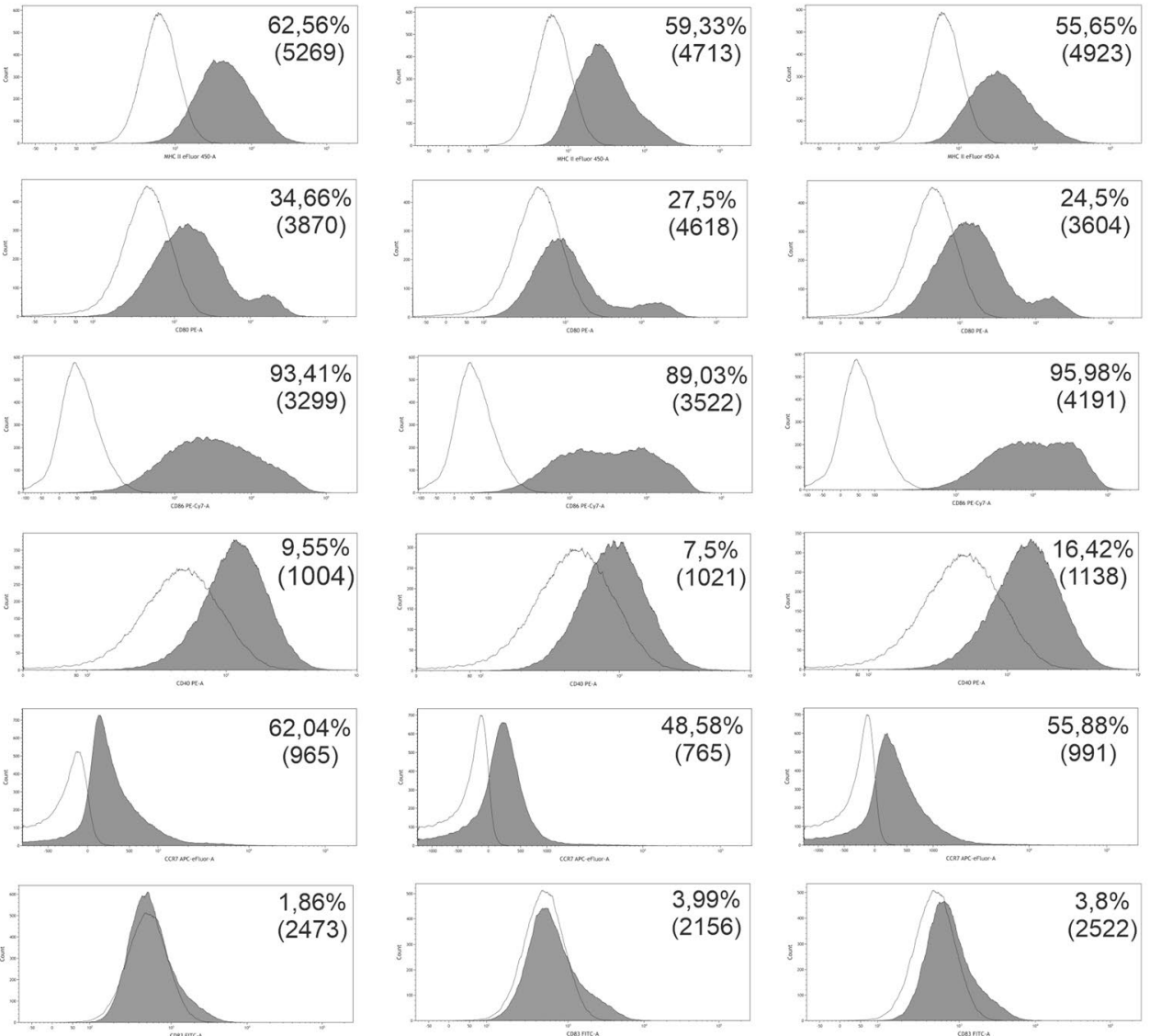

caosent


CD83
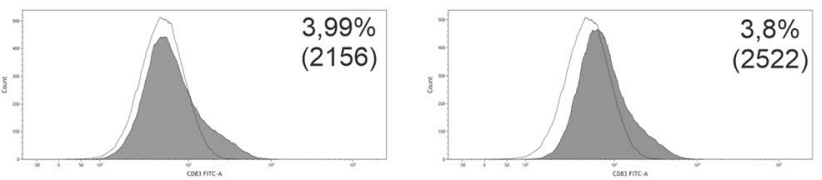

TLR2
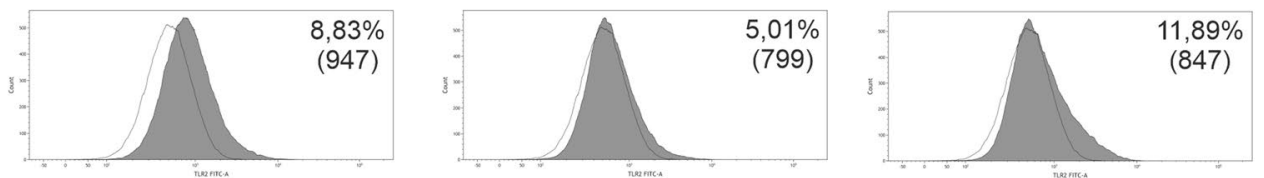

TLR4
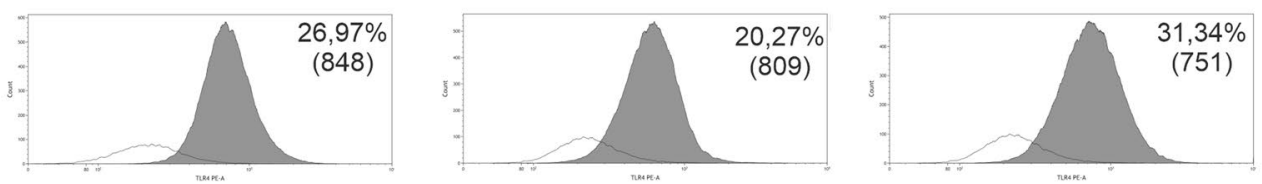

\section{Analysis of T Cell apoptosis}

The cells were harvested on day 5 of MLR, and apoptosis was determined by staining cells with a combination of Annexin-V FITC with propidium iodide using the
Annexin-V FITC Apoptosis Detection Kit (BD Pharmingen, USA), according to the manufacturers' protocols. The cells were co-stained with CD3-APC. Additionally, cells were labelled with CD4-FITC (clone: RPA-T4, eBioscience, USA), CD8-APC (clone: RPA-T8, eBioscience, USA), 
४Fig. 1 Effects of Rapa and CsA on the expression of DCs surface markers. Immature DCs were differentiated in the environment of immunosuppressive agents: Rapa (Rapa-DC) or CsA (CsA-DC) and without drugs (DC). Gating strategy for flow cytometric analysis of DCs: a time gate was initially applied to exclude any electronic noise and artifact (not shown here). Next, based on size and granularity, DCs were gated in a forward scatter area (FSC-A) versus side scatter area (SSC-A) plot. Then, doublet cells were excluded using FSC-A/ FSC-height (FSC-H) parameters. Within the singlet cell population CD11 ${ }^{+}$DCs were gated (A), followed by expression of individual markers shown on representative histograms for DC, Rapa-DC and CsA-DC (B). The averages of the percentage of positively labelled $\mathrm{CD} 11 \mathrm{c}^{+}$DCs and mean fluorescence intensity in bracket 7-14 different donors are reported on each histogram. The white shade indicates FMO control. Representative dot plots are presented

CD95-PE (clone: DX2, BD Pharmingen, USA) or CD95LPE (clone: NOK-1, BioLegend, USA) to identify T cells and CD11c-APC, CD95L-PE, Lineage Cocktail 1 (lin 1; CD3, CD14, CD16, CD19, CD20, CD56)-FITC (BD Pharmingen, USA) to identify DCs. The results were acquired and analyzed as described above.

\section{Analysis of Treg Induction}

Treg were identified after 5 days of coculture with DC, Rapa-DC or CsA-DC by staining cells with the following fluorochrome-conjugated monoclonal antibodies according to the manufacturers' protocols: CD3-PerCP (clone: SK7, BD Pharmingen, USA), CD4-FITC, CD8-APC, CD25APC or PE (clone: 2A3, BD Pharmingen, USA), CD28FITC (clone: CD28.2, BD Pharmingen, USA), CD127eFluor450 (clone: eBioRDR5, eBioscience). Intracellular analysis of Foxp3-PE (clone: 236A/E7, eBioscience, USA) was performed after fixation and permeabilization, using the FoxP3/Transcription Factor Staining Buffer Set (eBioscience, USA). The results were acquired and analyzed as described above.

\section{Statistical Analysis}

Results are given as means \pm standard deviations (SD) for $n$ samples per group. Statistical analysis was performed by the non-parametric Wilcoxon matched pair test using GraphPad Prism 8 software (GraphPad Software). A $p$ value of $<0.05$ was considered statistically significant.

\section{Results}

\section{Effects of Rapa and CsA on DC Differentiation}

To confirm whether Rapa or CsA affect the differentiation of DCs from monocytes, monocytes were cultured with granulocyte-macrophage colony-stimulating factor (GM-CSF) and IL-4 (DC; control DC) with Rapa (Rapa-DC) or CsA (CsA-DC). To identify immature monocyte-derived DCs, the $\mathrm{CD} 1 \mathrm{c}^{+} \mathrm{CD} 11 \mathrm{c}^{+} \mathrm{CD} 14^{-}$cells were analysed. The presence of CsA during the DC differentiation procedure resulted in a significantly lower percentage of $\mathrm{CD} 1 \mathrm{c}^{+} \mathrm{CD} 11 \mathrm{c}^{+} \mathrm{CD} 14^{-} \mathrm{DCs}$ compared to Rapa-DC and Control DC. In contrast, Rapa promoted the differentiation of monocyte-derived DCs (Fig. S1).

\section{Phenotype of Rapa-DC and CsA-DC}

To determine the surface phenotype, the expression of markers associated with T cell activation (CD40, CD80, CD83, CD86 and MHC II), DC migration (CCR7) and activation (TLR2, TLR4) was determined. Compared to the Control DC, the Rapa-DC were not significantly phenotypically different but demonstrated a higher CD80 MFI. The CsA-DC showed a significantly lower percentage of CD80-positive cells, but higher percentages of CD86 ${ }^{+}$and CD $40^{+}$DCs and their MFI values. Both immunosuppressive agents significantly reduced the percentage of $\mathrm{CD} 11 \mathrm{c}^{+} \mathrm{CCR} 7^{+} \mathrm{DCs}$ and significantly increased that of $\mathrm{CD} 11 \mathrm{c}^{+} \mathrm{CD} 83^{+} \mathrm{DCs}$. In contrast, only Rapa-DC showed a significantly lower expression of TLR2 and TLR4 (Fig. 1).

\section{Cytokine Production by Rapa-DC and CsA-DC}

The production of IL-4, IL-10, TGF- $\beta$, IL-6 and IL-12p70 was compared between the DC types. Only IL-10 production was found to be lower in Rapa-DC than in DC and CsA-DC (Fig. 2). No significant changes in the production of other cytokines were associated with Rapa or CsA treatment during DC differentiation. In contrast, IL-12p70 was notably undetectable in all culture conditions (data not shown).

\section{The Phagocytic Capacity of Rapa-DC and CsA-DC}

To determine the phagocytic capacity of Rapa-DC and CsA-DC, cellular FITC-dextran uptake was measured and the expression of phagocytosis receptors CD36 and DEC205 was determined by flow cytometry. The percentages of phagocytosing DCs, i.e. the percentage of CD11 ${ }^{+}$FITC-dextran ${ }^{+}$cells, were significantly lower in the Rapa and CsA-treated DC culture compared to controls (Fig. 3A). Similar results were observed for FITC-dextran uptake by DCs (Fig. 3B).

A significantly higher percentage of $\mathrm{CD} 11 \mathrm{c}^{+} \mathrm{CD} 36^{+}$ was observed for Rapa-DC compared to Control DC. No significant differences in CD36 MFI value were found between the examined DCs. The presence of Rapa or CsA during DC differentiation significantly decreased the percentage of CD11 $\mathrm{c}^{+} \mathrm{DEC} 205^{+}$DCs. However, significantly lower DEC205 MFI values were noted only in CsA-DC 
Fig. 2 Effects of Rapa and CsA on the cytokine production by immature DCs. Immature DCs were differentiated in the environment of immunosuppressive agents: Rapa (Rapa-DC) or CsA (CsA-DC) and without drugs (DC). Cytokine expression was measured by intracellular staining (IL-4; $\mathbf{A}$ ) or by ELISA of culture supernatants (IL-10, TGF- $\beta$ and IL-6; B-D, respectively). Results are the averages $\pm \mathrm{SD}$ of the percentage of positively labelled CD11 $\mathrm{c}^{+} \mathrm{DCs}$ $(\mathbf{A} ; n=5)$ or cytokine secretion $(\mathbf{B}-\mathbf{D} ; n=19) .{ }^{* *} p \leq 0.01$; $p$ values were calculated by Wilcoxon matched pair test
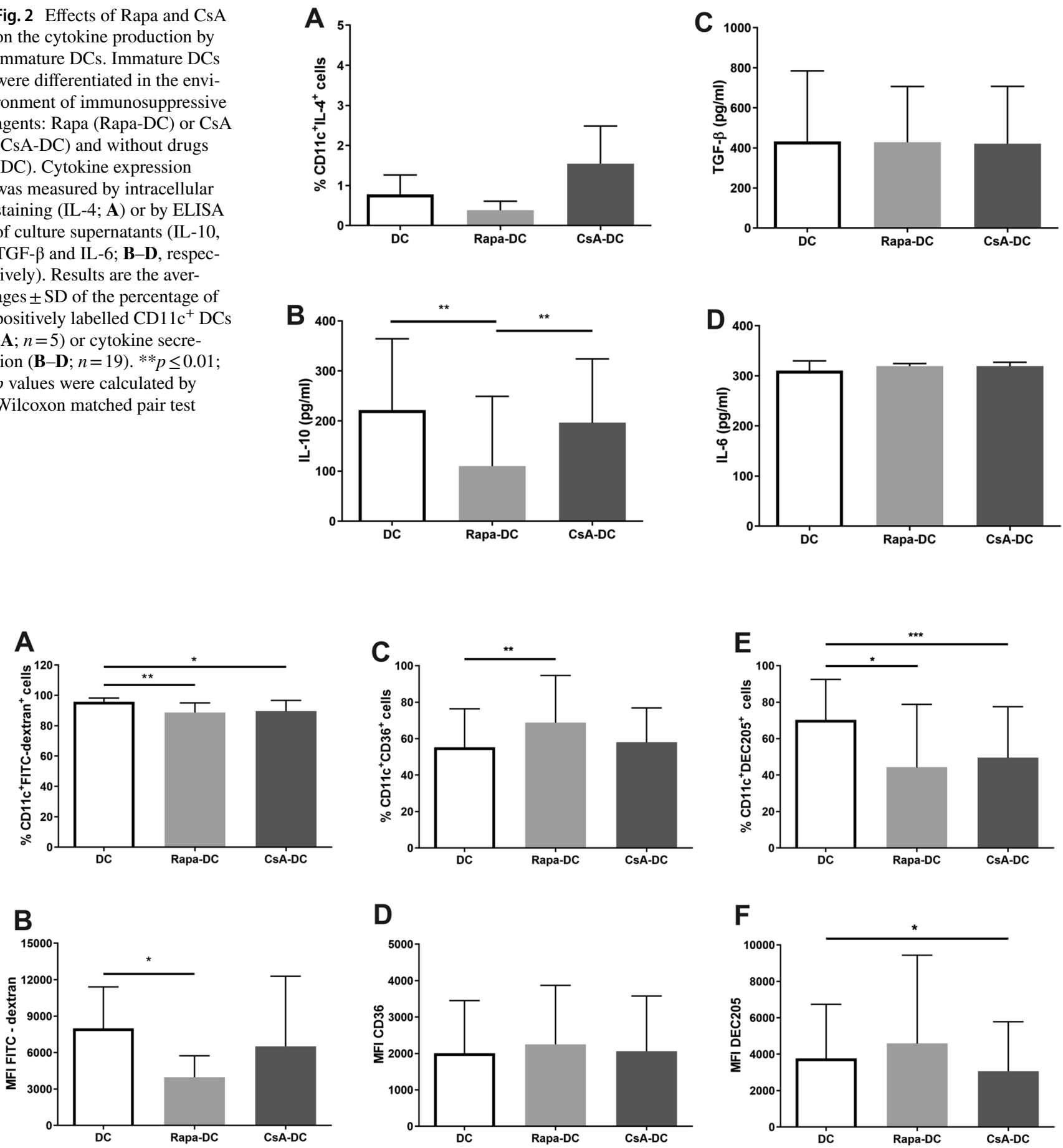

Fig. 3 Effects of Rapa and CsA on phagocytic capacity of DCs. Immature DCs were differentiated in the environment of immunosuppressive agents: Rapa (Rapa-DC) or CsA (CsA-DC) and without drugs (DC). Cellular FITC-dextran uptake $(\mathbf{A}, \mathbf{B} ; n=7)$ and the expression of phagocytosis receptors: $\operatorname{CD} 36(\mathbf{C}, \mathbf{D} ; n=10)$ and
DEC205 (F, G; $n=11)$ were determined by flow cytometry. Results are the averages \pm SD of the percentage of positively labelled CD11 $\mathrm{c}^{+}$ DCs and mean fluorescence intensity (MFI). ${ }^{*} p \leq 0.05, * * p \leq 0.01$, $*_{* *} p \leq 0.001 ; p$ values were calculated by Wilcoxon matched pair test 
(Fig. 3C-F). Taken together these results suggest that RapaDC and CsA-DC demonstrate decreased phagocytic capacity compared to the Control DC.

\section{Effects of Rapa and CsA on DC Activation}

To evaluate whether DCs differentiated in the environment with Rapa or CsA were resistant to an exogenous maturation stimulus, immature DCs were activated with LPS. The cell-surface phenotype and level of cytokine production were compared between immature and LPS-activated DCs to verify the process of DC maturation. After LPS activation, only the MFI values were significantly higher compared to immature DCs for all examined receptors. Additionally, significantly lower IL-10, TGF- $\beta$ and IL-6 levels were observed in all LPS-activated DC culture supernatants compared with the immature cultures (data not shown).

\section{Phenotype of LPS-Activated Rapa-DC and CsA-DC}

The maturation state of Rapa-DC and CsA-DC was determined by changes in the expression of surface markers. The percentage of LPS-activated DCs with $\mathrm{CD} 11 \mathrm{c}^{+} \mathrm{MHCII}^{+} \mathrm{CD} 80^{+} \mathrm{CD} 86^{+} \mathrm{CD} 83^{+} \mathrm{CCR} 7^{+}$phenotype was also determined; however, no significant differences were found between the Control DC group and the cultures treated with immunosuppressive agents (data not shown).

The Rapa-DC + LPS and CsA-DC + LPS groups demonstrated reduced, or comparable, expression of surface markers (both percentage positive cells and MFI values) to the control LPS-activated DCs. In particular, Rapa significantly decreased the percentage of DCs with MHC II and CD40 expression, as well as MHC II MFI values. CsA significantly decreased both the percentage of positive cells and MFI values of $\mathrm{CD} 11 \mathrm{c}^{+} \mathrm{MHC} \mathrm{II}{ }^{+}$and $\mathrm{CD} 11 \mathrm{c}^{+} \mathrm{CD} 80^{+}$DCs. At the same time, Rapa-DC + LPS demonstrated a significantly higher CCR7 MFI value. In contrast, the presence of Rapa or CsA alone during LPS activation did not affect the expression of the examined markers in DCs (Table 1).

\section{Cytokine Production by LPS-Activated Rapa-DC and CsA-DC}

The next stage examined the level of anti- and pro-inflammatory cytokine production by LPS-activated DCs. The results indicate no statistically significant differences in the percentage of $\mathrm{CD} 11 \mathrm{c}^{+} \mathrm{IL}-4^{+}$cells (LPS-activated DCs with intracellular IL-4 expression) between individual cultures; however, the percentage of these cells was almost eight times higher in CsA-DC+ LPS than in Rapa-DC + LPS (Fig. 4A). Similar as for immature DCs, we observed a statistically significant lower levels of IL-10 and additionally IL-6 in supernatants of Rapa-DC + LPS compared to DC + LPS and

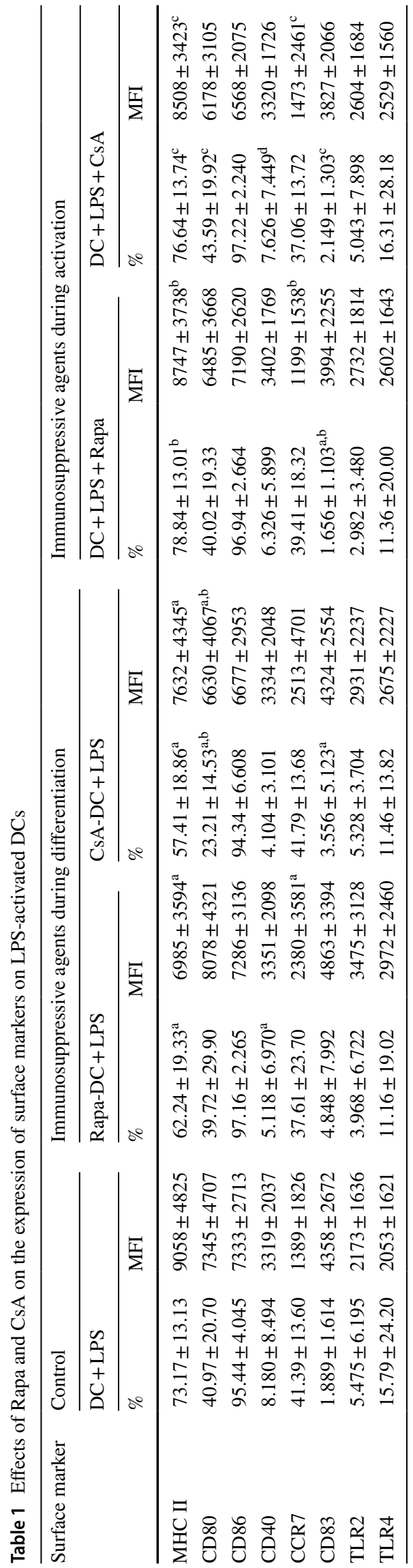



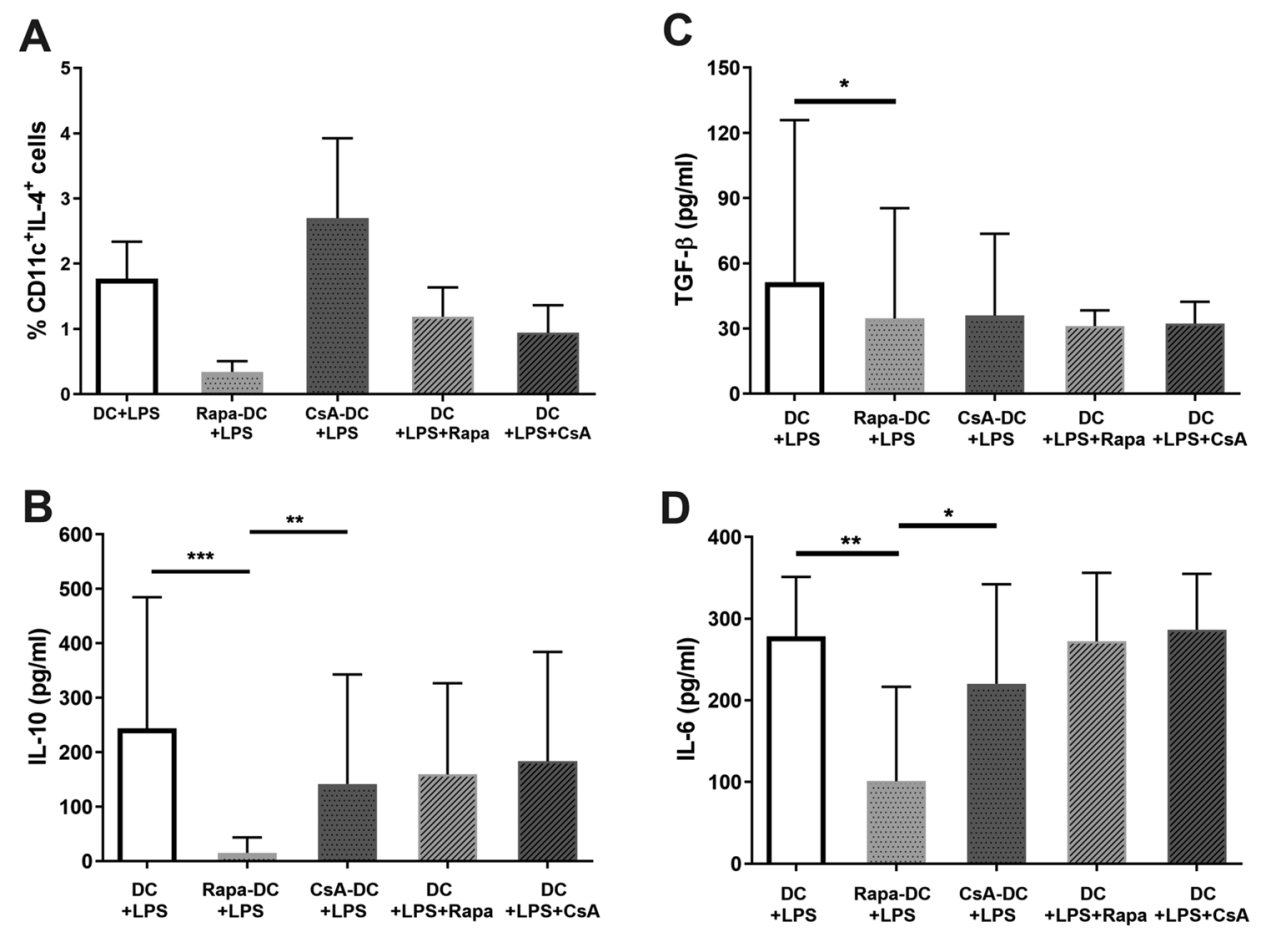

Fig. 4 Effects of Rapa and CsA on the cytokine production by LPSactivated DCs. Immature DCs generated in the environment of: Rapa (Rapa-DC+LPS), CsA (CsA-DC+LPS) and without drugs $(\mathrm{DC}+\mathrm{LPS})$ were activated with LPS. Additionally, DCs, which differentiated without drugs, were activated with LPS simultaneously with Rapa (DC+LPS + Rapa) or CsA (DC + LPS + CsA). Cytokine

expression was measured by intracellular staining (IL-4; A) or by ELISA of culture supernatants (IL-10, TGF- $\beta$ and IL-6; B-D, respectively). Results are the averages \pm SD of the percentage of positively labelled CD11 ${ }^{+}$DCs $(\mathbf{A})$ or cytokine secretion $(\mathbf{B}-\mathbf{D})$ from at least five different donors. ${ }^{*} p \leq 0.05, * * p \leq 0.01, * * * p \leq 0.001 ; p$ values were calculated by Wilcoxon matched pair test

CsA-DC + LPS and decrease TGF- $\beta$ compared to control (Fig. 4B-D). IL-12p70 was notably undetectable in all culture conditions (data not shown). In addition, no significant differences in cytokine production were found when immunosuppressive agents were added simultaneously with LPS (i.e. DC + LPS + Rapa and DC + LPS + CsA).

\section{Effects of Rapa-DC and CsA-DC on T Cell Activation and Function}

MLR cultures were performed to examine the induction of various mechanisms by Rapa-DC and CsA-DC. The levels of $\mathrm{T}$ cell activation markers, such as CD69 and CD25, were measured to determine the ability of Rapa-DC and CsA-DC to activate $\mathrm{T}$ cells. The results indicate that only the percentage of $\mathrm{CD} 3{ }^{+} \mathrm{CD} 69^{+}$cells in CsA-DC:T culture was significantly lower compared to controls. In addition, no significant differences in CD25 expression were observed (Fig. S2).

To further investigate the effect of Rapa-DC and CsA-DC on $\mathrm{T}$ cell activation, $\mathrm{T}$ cell proliferation was assessed; the findings revealed no significant difference in the percentage of proliferation of $T$ cells (data not shown). In addition, when Rapa or CsA was present during DC differentiation, significantly lower percentages of CD $11 \mathrm{c}^{+} \mathrm{PD}-\mathrm{L} 1^{+} \mathrm{DCs}$ and

PD-L1 MFI values were noted for immature DCs (Fig. 5). PD-L1 inhibits T cell activation by interacting with its ligand PD-1 on T cells.

To gain a deeper insight into the ability of Rapa-DC and CsA-DC to induce $\mathrm{T}$ cell apoptosis, the expression of two death-inducting receptors was analysed: CD95 (Fas) on T cells and CD95L (FasL) on DCs. It was found that for both the $\mathrm{CD} 4^{+}$and $\mathrm{CD} 8^{+} \mathrm{T}$ cell populations, the percentage of CD95-postive cells and MFI values were significantly lower in the Rapa-DC:T and CsA-DC:T cultures compared to the controls (Fig. 6). As CD95L expression may increase during $\mathrm{T}$ cell activation, this was also tested. Our results indicate a slight but statistically insignificant increase in the percentage of $\mathrm{CD} 4{ }^{+} \mathrm{CD} 95 \mathrm{~L}^{+}$and $\mathrm{CD} 8{ }^{+} \mathrm{CD} 95 \mathrm{~L}^{+}$in MLR cultures with Rapa-DC and CsA-DC compared to controls (data not shown). No significant differences were found in the percentage of $\operatorname{lin}^{-} \mathrm{CD} 11 \mathrm{c}^{+} \mathrm{CD} 95 \mathrm{~L}^{+} \mathrm{DCs}$ in MLR cultures. Only the MFI value of CD95L was significantly higher in the CsADC:T culture compared to Rapa-DC:T (Fig. S3). Finally, no statistically significant differences in the percentages of live, necrotic or apoptotic $\mathrm{T}$ cells were found between the RapaDC:T and CsA-DC:T cultures (data not shown).

To determine whether the presence of Rapa-DC or CsA-DC in MLR cultures may increase the percentage 


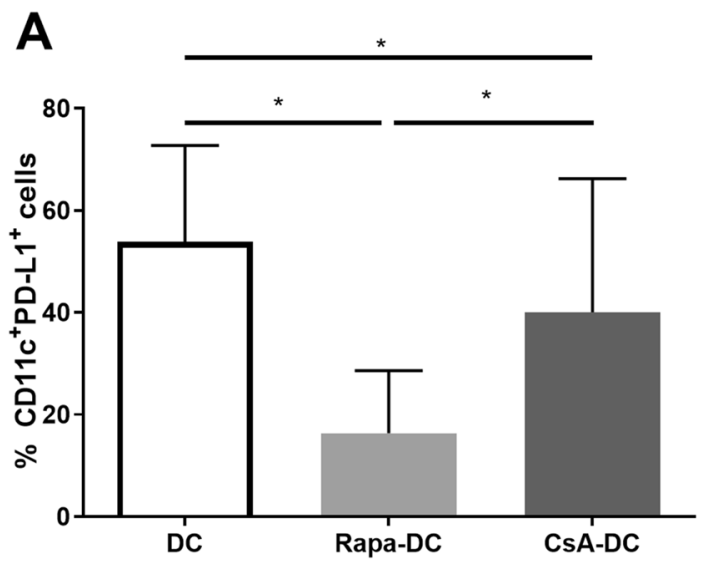

Fig. 5 Effects of Rapa and CsA on PD-L1 expression on DCs. Immature DCs were differentiated in the environment of immunosuppressive agents: Rapa (Rapa-DC) or CsA (CsA-DC) and without drugs (DC). Expression of PD-L1 was determined by flow cytometry.
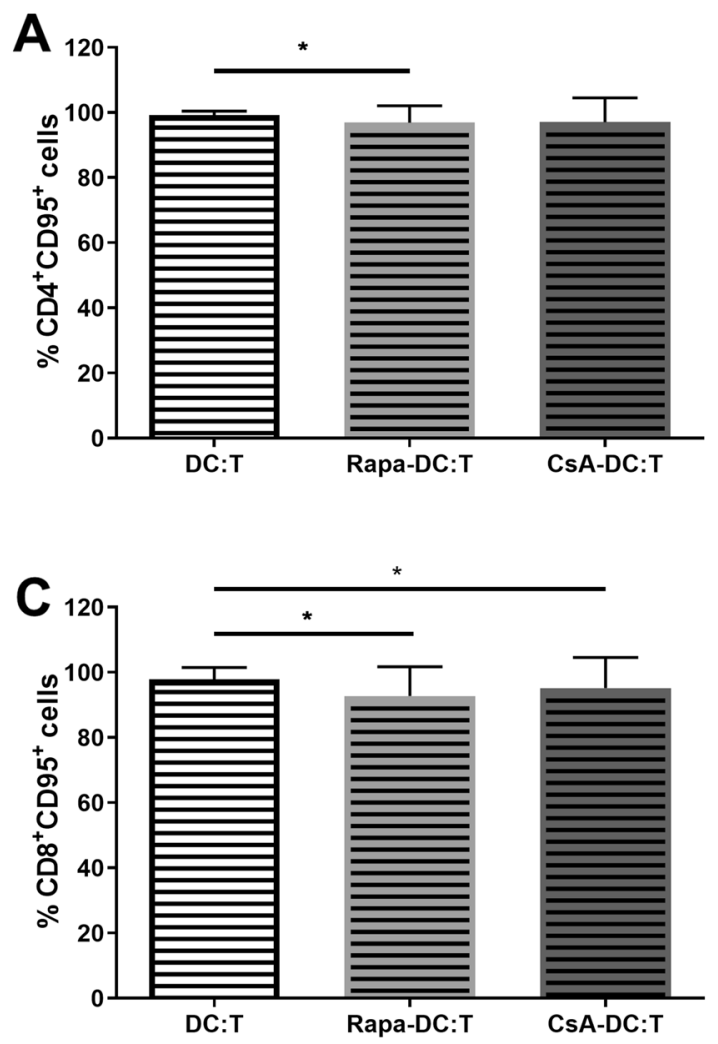

Fig. 6 Effects of Rapa-DC and CsA-DC on the expression of CD95 on $\mathrm{CD}^{+}$and $\mathrm{CD} 8^{+} \mathrm{T}$ cells. Immature DCs, Rapa-DC and CsA-DC were cocultured with T cells. Expression of CD95 was determined by flow cytometry. Results are the averages \pm SD of the percentage of

of Treg cell populations, Tregs $\mathrm{CD} 4{ }^{+} \mathrm{CD} 25^{\text {high }} \mathrm{Foxp} 3^{+}$, $\mathrm{CD} 8^{+} \mathrm{CD} 25^{+} \mathrm{CD} 28^{+}$and $\mathrm{CD} 8{ }^{+} \mathrm{CD} 25^{-} \mathrm{CD} 28^{-}$suppressor $\mathrm{T}$ cells were studied. After 5 days of MLR culture, a significant increase in the percentage of $\mathrm{CD} 4{ }^{+} \mathrm{CD} 25^{\text {high }} \mathrm{Foxp} 3^{+}$Tregs

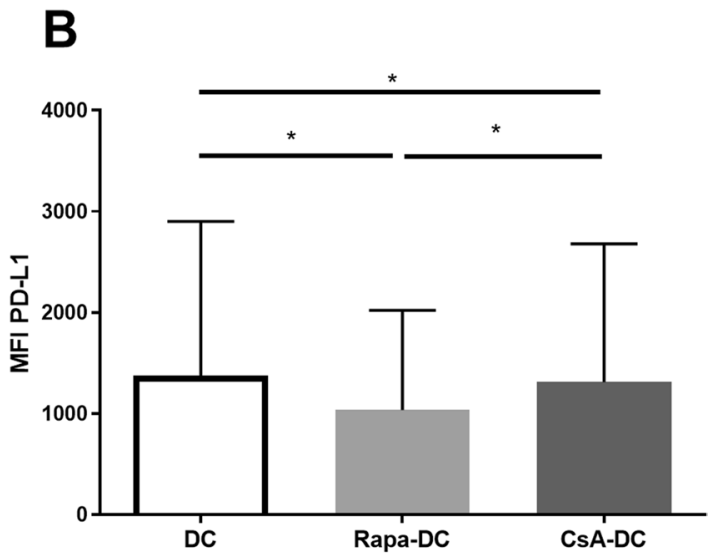

Results are the averages \pm SD of the percentage of CD11 ${ }^{+} \mathrm{PD}-\mathrm{L}^{+}$ DCs (A) and PD-L1 mean fluorescence intensity (MFI; B) from nine different donors. ${ }^{*} p \leq 0.05 ; p$ values were calculated by Wilcoxon matched pair test
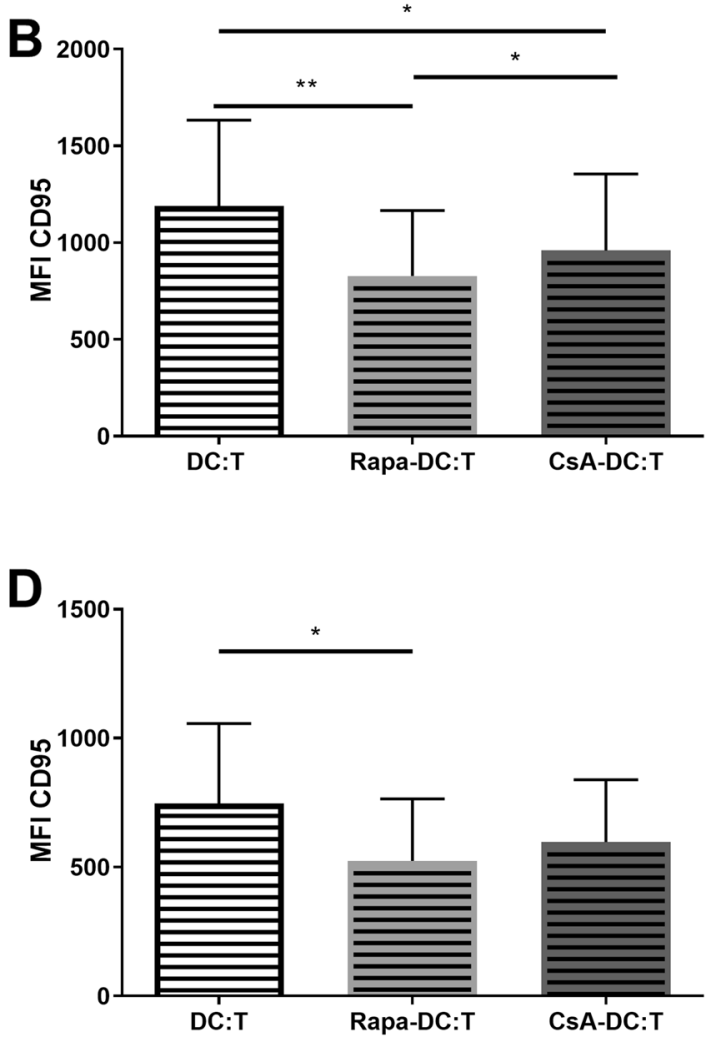

positively labelled $\mathrm{CD}^{+}(\mathbf{A})$ or $\mathrm{CD}^{+}(\mathbf{C}) \mathrm{T}$ cells and mean fluorescence intensity $(\mathrm{MFI})$ for $\mathrm{CD}^{+}(\mathbf{B})$ or $\mathrm{CD}^{+}(\mathbf{D}) \mathrm{T}$ cells, from ten different donors. $* p \leq 0.05$, $* * \leq 0.01 ; p$ values were calculated by Wilcoxon matched pair test

was observed for both sets of $\mathrm{T}$ cells, i.e. those stimulated by Rapa-DC or by CsA-DC, compared to controls (Fig. 7A). In addition, the $\mathrm{CD} 4{ }^{+} \mathrm{CD} 25^{\text {high }} \mathrm{Foxp} 3^{+}$Tregs demonstrated a significantly higher CD25 MFI value when cultured with 

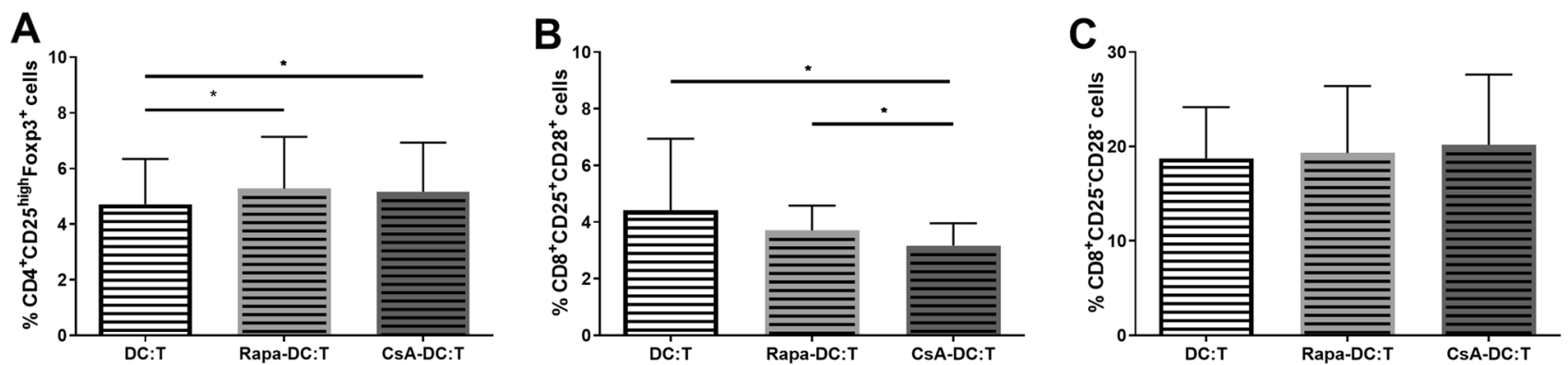

Fig. 7 Effects of Rapa-DC and CsA-DC on $\mathrm{T}$ regulatory cells populations. Immature DCs, Rapa-DC and CsA-DC were cocultured with $\mathrm{T}$ cells. The percentage of $\mathrm{CD} 4^{+} \mathrm{CD} 25^{\text {high }} \mathrm{Foxp}^{+}(\mathbf{A})$, $\mathrm{CD} 8{ }^{+} \mathrm{CD} 25^{+} \mathrm{CD} 28^{+}(\mathbf{B})$ and $\mathrm{CD} 8^{+} \mathrm{CD} 25^{-} \mathrm{CD} 28^{-}(\mathbf{C}) \mathrm{T}$ cells were

Rapa-DC compared to controls and CsA-DC:T. Also, the Foxp3 MFI value was significantly higher in Tregs from Rapa-DC:T than CsA-DC:T (Fig. S4).

Then, as shown in Fig. 7, only the percentage of $\mathrm{CD} 8^{+} \mathrm{CD} 25^{+} \mathrm{CD} 28^{+} \mathrm{T}$ cells was significantly decreased in culture with CsA-DC, compared to controls and RapaDC. No differences were found in the CD25 and CD28 MFI values.

Finally, the production of a Th1- or Th2-characteristic cytokine profile was determined to assess Th2 cell activation. No significant differences were observed in IL-4 production by $\mathrm{T}$ cells under any culture conditions (Fig. 8C). However, significantly lower levels of other Th1 (IL-2, IFN$\gamma$ ) and Th2 cytokines (IL-5, IL-10, IL-13) were detected in supernatants from $\mathrm{T}$ cells cocultured with Rapa- or CsA-DC (Fig. 8).

\section{Discussion}

Possibly the greatest challenge faced by transplantation medicine in the twenty-first century is the induction of immune tolerance following organ transplantation. One important discovery in this regard is that tolDCs may not only induce transplant tolerance, but may also avoid the use of immunosuppressive agents and minimize immunosuppressionrelated side effects. Hence, attempts to develop tolDC-based therapies are required to improve long-term graft outcome.

Our findings indicate that the presence of Rapa during DC differentiation increased the percentage of $\mathrm{CD} 1 \mathrm{c}^{+} \mathrm{CD} 11 \mathrm{c}^{+} \mathrm{CD} 14^{-} \mathrm{DCs}$, whereas CsA decreased it. These suggest that the environment of Rapa favours the differentiation of monocytes into immature DCs with a set of markers distinctive for myeloid DCs (CD11c and CD1c), but with a lack of monocyte marker CD14. Similarly, increased expression of CD1c was reported on Rapa-DC; it is possible that this could be correlated with regulatory cell infiltration (Monti et al. 2003). determined by flow cytometry. Results are the averages \pm SD from ten different donors. ${ }^{*} p \leq 0.05 ; p$ values were calculated by Wilcoxon matched pair test

The presence of Rapa during differentiation did not significantly affect the DC expression of surface markers related to T cell activation, such as MHC II, CD86 and CD40, except CD80. These findings are not in line with those of previous studies indicating that Rapa decreases the level of MHC II, CD86 and CD40 costimulatory molecules, with CD80 expression demonstrating considerable variance (Fedoric and Krishnan 2008; Haidinger et al. 2010; Monti et al. 2003). In addition, no changes in the expression of investigated costimulatory molecules during Rapa treatment were noted by Woltman et al. (2001). However, this variation may due to the different cell culture conditions, i.e. where Rapa was added after DC differentiation.

Our present findings indicate that the Rapa-DC culture displayed a significant decrease of CD80 expression. CD80 and CD86 are ligands of CD28 and cytotoxic T-lymphocyteassociated protein 4 (CTLA-4) receptors on T cells (Hubo et al. 2013). CD80 has greater affinity for CTLA-4 (Sansom and Walker 2006): Signalling by the CD80/CTLA-4 pathway can promote the generation and suppressive activity of Tregs, and signalling by CD86/CD28 induces T cell activation (Bhatia et al. 2006; Hubo et al. 2013; Pletinckx et al. 2011; Sansom and Walker 2006; Zheng et al. 2004). Experimental transplantology models suggest that CTLA-4 signalling is needed for immune tolerance induction and can prevent graft rejection (Judge et al. 1999; Yamada et al. 2001), whereas DC with CD80 expression but without CD86 can decrease rejection to xeno-islets (Ke et al. 2016).

The presence of CsA during DC differentiation resulted in increased CD86 and CD40 expression as well as decreased expression of CD80. Both CD86 and CD40 are involved in enhancing T cell activation (Hubo et al. 2013). The obtained results may suggest that CsA do not maintain the tolerogenic phenotype of DCs. Although the effects of CsA on CD86 and CD40 expression were not confirmed by previous studies (Duperrier et al. 2002; Fedoric and Krishnan 2008; Szabo et al. 2001; Woltman et al. 2000), this may be due to the different concentration of CsA used between the studies. 



Fig. 8 Effects of Rapa-DC and CsA-DC on the production of Th1and Th2-characteristic cytokines. Immature DCs, Rapa-DC and CsADC were cocultured with T cells. Cytokine expression was measured by ELISA of culture supernatants for the presence of Th1 cytokines:

DC differentiation in the presence of Rapa resulted in a decreased percentage of DCs with TLR2, TLR4 and CCR7 expression. Many of the studies indicate that increased TLR2 and TLR4 expression on mononuclear cells may contribute to allograft rejection (Castillo et al. 2010; Deng et al. 2007; McDaniel et al. 2010; Methe et al. 2004; Testro et al. 2011). Therefore, the decreased TLR 2 and TLR 4 expression observed on Rapa-treated DCs may protect the organ
IL-2 (A), IFN- $\gamma$ (B) and Th2 cytokines: IL-4 (C), IL-5 (D), IL-10 (E), IL-13 (F). Results are the averages \pm SD of cytokine secretion from 19 different donors. $* p \leq 0.05, * * p \leq 0.01 ; p$ values were calculated by Wilcoxon matched pair test

recipient from rejection, by minimizing the response of DCs to specified ligands and subsequent $\mathrm{T}$ cell activation. Moreover, Rapa-DC can be less sensitive to activation signals through TLR, as Rapa may be able to induce the generation of maturation-resistant DCs. However, TLR signalling increases DC migration toward lymph nodes for antigen presentation (Howell et al. 2014). The decreased expression of CCR7 on Rapa-DC may result in reduced induction 
of immune response due to weak antigen presentation and DC migration. Those results are correlated with decreased expression of TLR 2 and TLR 4 as well as of the costimulatory molecules typical for immature DCs.

The elevated percentages of CD83-positive Rapa-DC and CsA-DC could act as a balance to the tolerogenic potential of Rapa and CsA, as CD83 is the marker for mature DCs and can act as an essential enhancer during $\mathrm{T}$ cell activation (Prechtel and Steinkasserer 2007). However, Kryczanowsky et al. (2016), report that tolDCs with high CD83 expression generated stronger regulatory function of induced Tregs than DCs with low CD83 expression. In other studies, the extracellular CD83 domain, as a soluble protein, inhibited DC maturation and T cell proliferation via DCs, thus demonstrating the strong immunosuppressive activity of CD83 (Fujimoto and Tedder 2006; Lechmann et al. 2001, 2002). It has been used in transplantation, where treatment with soluble CD83 has induced tolDCs that may promote tolerance and prevent allograft rejection (Ge et al. 2010; Lan et al. 2010; Xu et al. 2007; Yang et al. 2015).

The presence of Rapa or CsA during DC differentiation did not affect the production of anti-inflammatory cytokines (IL-4, TGF- $\beta$ ); however, the IL-10 level was lowered in the Rapa-treated culture. Comparable outcomes were previously observed in mouse DC cultures (Turnquist et al. 2010). Similarly, no significant differences were observed in proinflammatory cytokine production. In addition, the secretion of IL-12p70 was not detected in any cases. Our findings are in line with previous reports (Abdul et al. 2008; Ohtani et al. 2008; Sauma et al. 2003; Szabo et al. 2001; Turnquist et al. 2010). A common feature of tolerogenic DCs is the lack of IL-12. The obtained results could suggest that for DC tolerogenic properties to be maintained, cytokine levels may need to remain at those observed for immature DCs (Morelli and Thomson 2007; Steinman et al. 2003). In addition, some studies suggest that anti-inflammatory cytokine production is not needed to ensure the tolerogenic potential of RapaDC and CsA-DC (Monti et al. 2003; Naranjo-Gómez et al. 2011).

In our present study, both Rapa-DC and CsA-DC showed decreased phagocytic capacity and DEC205 expression. Comparable outcomes have also been observed in mouse and human DC studies (Abdul et al. 2008; Hackstein et al. 2002; Monti et al. 2003; Tajima et al. 2003). Decreased phagocytosis is a very important property of tolDCs, because it may also decrease the probability of $\mathrm{T}$ cell activation (Monti et al. 2003).

To confirm whether Rapa or CsA may generate maturation-resistant tolDCs, the study also evaluated phenotype and level of cytokine production by LPS-activated DCs differentiated in the presence of drugs. In addition, we also examined whether the presence of immunosuppressive agents during activation alone may generate maturation-resistant
tolDCs. Our results indicate that the presence of Rapa or CsA during DC differentiation had a stronger influence on surface receptor expression and cytokine production than the presence of immunosuppressants during DC activation; this is in line with previous reports about Rapa (Fedoric and Krishnan 2008; Haidinger et al. 2010; Monti et al. 2003).

Our findings demonstrate that the presence of Rapa or CsA during DC differentiation, in particular Rapa, can induce generation of partly maturation-resistant DCs after LPS activation. LPS-activated Rapa-DC demonstrated decreased expression of MHC II and CD40, and decreased secretion of IL-10, TGF- $\beta$ and IL-6. IL-12p70 was undetectable, which is in line with previous reports demonstrating the absence of IL-12, or decreased production, by activated Rapa-DC (Chen et al. 2004; Horibe et al. 2008; Monti et al. 2003; Naranjo-Gómez et al. 2011; Pino-Lagos et al. 2010; Sauma et al. 2003; Szabo et al. 2001;). Studies on animal models confirmed that the presence of Rapa during DC differentiation results in the generation of maturation-resistant DCs after LPS activation (Hackstein et al. 2003; Horibe et al. 2008; Taner et al. 2005). Furthermore, an infusion of Rapa-DC after composite tissue transplantation can prevent graft rejection (Ikeguchi et al. 2008). Similar findings were noted by Haidinger et al. (2010) in human DCs, where MHC II expression and IL-6 and IL-10 production were all decreased. In the case of CsA, while they do not appear to influence human DC activation with LPS (Szabo et al. 2001; Woltman et al. 2000), some mouse-based studies have found it to influence DC maturation (Pino-Lagos et al. 2010; Sauma et al. 2003).

An interesting observation is the increase in CCR7 expression associated with LPS-activated Rapa-DC. This is an important consideration in the clinical application of tolDCs, as CCR7-dependent migration toward secondary lymphoid organs is required for efficient induction of functional Tregs. Hence, the potential for migration of Rapa-DC may suggests that Rapa has immunosuppressive potential, as confirmed previously (Adnan et al. 2016; Förster 2008; Stallone et al. 2016). It can also be indicative of the generation of semi-mature DCs, cells which may induce Tregs (Lutz et al. 2002; Lutz 2012). Therefore, increasing the CCR7 expression on DCs can play an important role in tolerance promotion. Comparable outcomes were observed in various DC culture models. Rapa treatment was found to enhance the migration of activated DCs, or at least not inhibit it; this migration was accompanied by CCR7 expression comparable to control values or higher (Adnan et al. 2016; Boks et al. 2012; Sordi et al. 2006; Stallone et al. 2016; Taner et al. 2005; Turnquist et al. 2007). In a study of LPS-activated DCs, Sordi et al. (2006) attribute CCR7 up-regulation to inhibition of IL-10 production, and suggest that IL-10 may inhibit CCR7 expression. Assuming this is the case, the increase in CCR7 expression observed in LPS-activated 
Rapa-DC in the present study may be due, at least partially, to a fall in IL-10 production.

The presence of Rapa during DC differentiation did not influence their potential for $\mathrm{T}$ cell activation, No changes in the expression of activation markers or percentage of proliferating T cells were observed. Previous studies indicate that immature Rapa-DC, both human and mouse, have a limited potential to induce $\mathrm{T}$ cell proliferation (Monti et al. 2003; Taner et al. 2005; Turnquist et al. 2007, 2010).

In addition, a significant decrease of PD-L1 expression was observed on immature Rapa-DC, which may suggest that Rapa does not influence the allostimulatory capacity of DCs. Previous studies confirm that PD-L1 expression is decreased on the surface of DCs during Rapa treatment (Boks et al. 2012; Haidinger et al. 2010; Macedo et al. 2013). However, our present findings indicate that Rapa decreased IL- 6 and IL-10 production by immature and LPSactivated DC. This may be associated with the low level of PD-L1 expression on Rapa-DC, because increased PD-L1 expression is correlated with high IL-6 and IL-10 production (Sumpter and Thomson 2011; Wolfle et al. 2011). Rosborough et al. (2013) report that Rapa inhibited mammalian target of rapamycin complex 1 and caused atypical reduction of IL-10 synthesis and PD-L1 expression on mouse DCs. It is possible that tolerogenic Rapa activity is not correlated with changes of PD-L1 expression.

In contrast to Rapa, CsA was found to inhibit $\mathrm{T}$ cell activation potential by the studied DC, which is due to the lower percentage of proliferating $\mathrm{T}$ cells and $\mathrm{CD} 3^{+} \mathrm{CD} 69^{+} \mathrm{T}$ cells in the CsA-DC culture. These results are in line with those of previous studies (Duperrier et al. 2002; Geng et al. 2008; Matsue et al. 2002; Szabo et al. 2001). Similarly, PD-L1 expression was significantly reduced on immature DC differentiated in the presence of CsA. Unfortunately, no data are available concerning the effects of CsA on PD-L1 expression on DCs. Only Geng et al. (2008) indicate that CsA does not appear to have an influence on PD-L1 expression in mouse DCs. Based on those results, it is likely that the PD-1/PD-L1 pathway inhibition mechanism does not play a crucial role in the tolerogenic influence of CsA-DC on T cell activation.

In addition, our findings indicate that DCs differentiated in the presence of immunosuppressive agents reduced the susceptibility of $\mathrm{T}$ cells to apoptosis via decreased CD95 expression on the $\mathrm{T}$ cell surface; however, they did not affect cell viability or apoptosis induction among T cells. Stenger et al. (2014) report that murine Rapa-DC promotes apoptosis of alloreactive T cells via induction of IFN- $\gamma$ production by the cells. Moreover, this induction also entails increased CD95 expression on $\mathrm{T}$ cells. The interaction between CD95 and $\mathrm{CD} 95 \mathrm{~L}$ is a significant mechanism of apoptosis promotion by DCs. Our results are in line with other studies indicating that Rapa-DC did not affect $\mathrm{T}$ cell apoptosis induction
(Naranjo-Gómez et al. 2011; Taner et al. 2005). However, no previous studies have examined this aspect of CsA-DC.

Our data confirm that Rapa can influence the ability of DCs to induce Tregs, which is in line with previous outcomes (Naranjo-Gómez et al. 2011; Turnquist et al. 2007, 2010). In our present study, CsA-DC also showed the ability to generate Treg cells; however, lower CD25 and Foxp3 expression was observed compared to $\mathrm{T}$ cells cultured with Rapa-DC. These results are in contrast to those of Fedoric and Krishnan (2008), who demonstrated that CsA-DC are unable to induce Treg generation, and those of Pino-Lagos et al. (2010), who found that murine CsA-treated DCs reduce the proliferation of Tregs. Any differences between studies can be attributed to heterogeneity regarding experimental protocols and drug concentrations.

Interestingly, the combination of higher $\mathrm{CD} 86$ and lower CD80 expression on CsA-DC surface did not influence the Treg generation potential of the DCs. Similarly, Pletinckx et al. (2011), suggest that DCs with moderate, or even high expression of CD80/CD86 costimulatory molecules are effective Treg inductors. This may suggest that the level of CD80/CD86 expression may not be crucial for Treg generation by DCs. In contrast, our present findings indicate that the Rapa-DCs demonstrating a similar CD80/CD86 expression profile to control immature DCs, induced a higher percentage of Tregs than the CsA-DCs.

Our results indicate that DCs differentiated in the environment of Rapa or CsA did not increase the percentage of studied $\mathrm{CD}^{+} \mathrm{T}$ cells, while coculture with CsA-DC significantly decreased the percentage of $\mathrm{CD} 8^{+} \mathrm{CD} 25^{+} \mathrm{CD} 28^{+}$ $\mathrm{T}$ cells. This could suggest that neither studied immunosuppressant affects the ability of DCs to induce generation of $\mathrm{CD} 8^{+} \mathrm{T}$ cells with regulatory function.

To assess Th2 cell activation and the allostimulatory capacity of DCs, it was also important to evaluate production of cytokines by $\mathrm{T}$ cells during DC-T cell interactions. While previous studies report decreased production of IL-2 and IFN- $\gamma$, characteristic of Th1, and IL-4, IL-5, IL-10 characteristic of Th2, most of them were observed in studies of activated DC (Monti et al. 2003; Naranjo-Gómez et al. 2011; Taner et al. 2005; Turnquist et al. 2010; Wang et al. 2009). A review of the few existing investigations of immature RapaDC cells suggests that they induce decreased production of IL-10 by T cells (Taner et al. 2005) with no effect on IFN- $\gamma$ and IL-4 production (Turnquist et al. 2010). Only Stenger et al. (2014), report a significant elevation of IFN- $\gamma$ synthesis by $\mathrm{T}$ cells, but this was associated with the interaction with IL-12 ${ }^{\text {hi }}$ Rapa-DC.

In line with Matsue et al. (2002) and Tajima et al. (2003), our results also indicate decreased production of IL-2 and IFN- $\gamma$ by T cells stimulated with CsA-DC, as well as lower production of the Th2-characteristic cytokines IL-5 and IL-13. This confirms the observations of Abdul et al. (2008), 
that neither CsA nor Rapa influence the ability of DCs to induce Th2 cells activation, and that they can even inhibit it. Moreover, the lack of IL-12 production by Rapa-DC and CsA-DC, a cytokine crucial in the development of the Th1 response, resulted in a weakening of the ability of RapaDC and CsA-DC to polarize T cells into a Th1 subpopulation; this may indicate a decreased allostimulatory ability by these DCs, and can be one of mechanisms underlying their tolerogenicity.

In conclusion, our results demonstrate that Rapa, in contrast to CsA, is effective at generating maturation-resistant DCs with tolerogenic properties, such as low expression of molecules associated with antigen presentation and $\mathrm{T}$ cell activation, low expression of TLR2 and TLR4 and decreased phagocytic capacity. Such Rapa-DCs induce Treg generation. In the case of CsA, it is not efficient at generating maturation-resistant tolDCs, but affects the ability of these cells to decrease Th1-characteristic cytokine production and induce Treg generation. Moreover, the presence of Rapa or CsA only during DC activation with LPS did not affect the generation of maturation-resistant DCs.

Supplementary Information The online version contains supplementary material available at https://doi.org/10.1007/s00005-021-00632-7.

Acknowledgements The authors would like to thank Lidia Malchar for expert technical assistance. The authors are also very grateful to Bożena Katarzyna Budziszewska and Katarzyna DonskowŁysoniewska for critically reading the manuscript.

Author Contributions MM conceived, designed and performed the experiments, analysed data and wrote the manuscript. MK, AJ, At and $\mathrm{ZK}$ performed experiments. MMC analysed the data and wrote the manuscript. KB contributed to design the DC culture model. GKK conceived and designed the experiments, analysed the data and corrected the manuscript.

Funding This work was supported by a grant from the National Science Centre, Poland; Preludium grant number no. 2012/05/N/NZ6/01046.

Data Availability Not applicable.

Code Availability Not applicable.

\section{Declarations}

Conflict of interest The authors declare no conflict of interest.

Ethics approval Not applicable.

Consent to participate Not applicable.

Consent for publication Not applicable.

Open Access This article is licensed under a Creative Commons Attribution 4.0 International License, which permits use, sharing, adaptation, distribution and reproduction in any medium or format, as long as you give appropriate credit to the original author(s) and the source, provide a link to the Creative Commons licence, and indicate if changes were made. The images or other third party material in this article are included in the article's Creative Commons licence, unless indicated otherwise in a credit line to the material. If material is not included in the article's Creative Commons licence and your intended use is not permitted by statutory regulation or exceeds the permitted use, you will need to obtain permission directly from the copyright holder. To view a copy of this licence, visit http://creativecommons.org/licenses/by/4.0/.

\section{References}

Abdul M, Charron D, Haziot A (2008) Selective effects of cyclosporine A on Th2-skewed dendritic cells matured with viral-like stimulus by means of Toll-like receptors. Transplantation $86: 880-884$. https://doi.org/10.1097/TP.0b013e3181861f1d

Adnan E, Matsumoto T, Ishizaki J et al (2016) Human tolerogenic dendritic cells generated with protein kinase $\mathrm{C}$ Inhibitor are optimal for functional regulatory $\mathrm{T}$ cell induction - a comparative study. Clin Immunol 173:96-108. https://doi.org/10.1016/j.clim. 2016.09.007

Bhatia S, Edidin M, Almo SC et al (2006) B7-1 and B7-2: similar costimulatory ligands with different biochemical, oligomeric and signaling propert. Immunol Lett 104:70-75. https://doi.org/10. 1016/j.imlet.2005.11.019

Boks MA, Kager-Groenland JR, Haasjes MSP et al (2012) IL-10-generated tolerogenic dendritic cells are optimal for functional regulatory $\mathrm{T}$ cell induction - a comparative study of human clinicalapplicable DC. Clin Immunol 142:332-342. https://doi.org/10. 1016/j.clim.2011.11.011

Cangemi M, Montico B, Faè DA et al (2019) Dissecting the multiplicity of immune effects of immunosuppressive drugs to better predict the risk of de novo malignancies in solid organ transplant patients. Front Oncol 9:160. https://doi.org/10.3389/fonc.2019. 00160

Castillo RO, Wang M, Ito T et al (2010) Acute rejection of small intestine allografts is associated with increased expression of Tolllike receptors. Transplant Proc 42:2676-2678. https://doi.org/10. 1016/j.transproceed.2010.05.157

Chen T, Guo J, Yang M et al (2004) Cyclosporin A impars dendritic cell migration by regulating chemokine receptor expression and inhibiting cyclooxygenase-2 expression. Blood 103:413-421. https://doi.org/10.1182/blood-2003-07-2412

Deng JF, Geng L, Qian YG et al (2007) The role of Toll-like receptors 2 and 4 in acute allograft rejection after liver transplantation. Transplant Proc 39:3222-3224. https://doi.org/10.1016/j.trans proceed.2007.02.102

Duperrier K, Farre A, Bienvenu J et al (2002) Cyclosporin A inhibits dendritic cell maturation promoted by TNF-alpha or LPS but not by double-stranded RNA or CD40L. J Leukoc Biol 72:953-961. http://www.ncbi.nlm.nih.gov/pubmed/12429717

Enderby C, Keller CA (2015) An overview of immunosuppression in solid organ transplantation. Am J Manag Care 21(1 suppl):s12-23

Fedoric B, Krishnan R (2008) Rapamycin downregulates the inhibitory receptors ILT2, ILT3, ILT4 on human dendritic cells and yet induces $\mathrm{T}$ cell hyporesponsiveness independent of FoxP3 induction. Immunol Lett 120:49-56. https://doi.org/10.1016/j.imlet. 2008.06.009

Förster R, Davalos-Misslitz AC, Rot A (2008) CCR7 and Its ligands: balancing immunity and tolerance. Nat Rev Immunol 8:362-371. https://doi.org/10.1038/nri2297

Fujimoto Y, Tedder TF (2006) CD83: A Regulatory molecule of the immune system with great potential for therapeutic application. J Med Dental Sci 53:85-91 
Ge W, Arp J, Lian D et al (2010) Immunosuppression involving soluble CD83 induces tolerogenic dendritic cells that prevent cardiac allograft rejection. Transplantation 90:1145-1156. https://doi.org/ 10.1097/TP.0b013e3181f95718

Geng L, Dong S, Fang Y et al (2008) Cyclosporin A up-regulates B7-DC expression on dendritic cells in an IL-4-dependent manner in vitro, which is associated with decreased allostimulatory capacity of dendritic cells. Immunopharmacol Immunotoxicol 30:399-409. https://doi.org/10.1080/08923970701812746

Hackstein H, Taner T, Logar AJ et al (2002) Rapamycin inhibits macropinocytosis and mannose receptor-mediated endocytosis by bone marrow-derived dendritic cells. Blood 100:1084-7108. https:// doi.org/10.1182/blood.V100.3.1084

Hackstein H, Taner T, Zahorchak AF et al (2003) Rapamycin inhibits IL-4-induced dendritic cell maturation in vitro and dendritic cell mobilization and function in vivo. Blood 101:4457-4463. https:// doi.org/10.1182/blood-2002-11-3370

Haidinger M, Poglitsch M, Geyeregger R et al (2010) A versatile role of mammalian target of rapamycin in human dendritic cell function and differentiation. J Immunol 185:3919-3931. https://doi.org/10. 4049/jimmunol.1000296

Horibe EK, Sacks J, Unadkat J et al (2008) Rapamycin-conditioned, alloantigen-pulsed dendritic cells promote indefinite survival of vascularized skin allografts in association with $\mathrm{T}$ regulatory cell expansion. Transpl Immunol 18:307-318. https://doi.org/10. 1016/j.trim.2007.10.007

Horton C, Shanmugarajah K, Fairchild PJ (2017) Harnessing the properties of dendritic cells in the pursuit of immunological tolerance. Biomed J 40:80-93. https://doi.org/10.1016/j.bj.2017.01.002

Howell J, Gow P, Angus PW et al (2014) Role of Toll-like receptors in liver transplantation. Liver Transpl 20:270-280. https://doi.org/ 10.1002/lt.23793

Hubo M, Trinschek B, Kryczanowsky F et al (2013) Costimulatory molecules on immunogenic versus tolerogenic human dendritic cells. Front Immunol 4:82. https://doi.org/10.3389/fimmu.2013. 00082

Ikeguchi R, Sacks JM, Unadkat JV et al (2008) Long-term survival of limb allografts induced by pharmacologically conditioned, donor alloantigen-pulsed dendritic cells without maintenance immunosuppression. Transplantation 85:237-246. https://doi.org/10.1097/ TP.0b013e31815e 870e

Judge TA, Wu Z, Zheng XG et al (1999) The role of CD80, CD86, and CTLA4 in alloimmune responses and the induction of long-term allograft survival. J Immunol 162:1947-1951. http://www.jimmu nol.org/content/162/4/1947.full

Ke N, Su A, Huang W et al (2016) Regulating the expression of CD80/ CD86 on dendritic cells to induce immune tolerance after xenoislet transplantation. Immunobiology 221:803-812. https://doi. org/10.1016/j.imbio.2016.02.002

Kryczanowsky F, Raker V, Graulich E et al (2016) IL-10-modulated human dendritic cells for clinical use: identification of a stable and migratory subset with improved tolerogenic activity. J Immunol 197:3607-3617. https://doi.org/10.4049/jimmunol.1501769

Lan Z, Ge W, Arp J et al (2010) Induction of kidney allograft tolerance by soluble $\mathrm{cd} 83$ associated with prevalence of tolerogenic dendritic cells and indoleamine 2,3-dioxygenase. Transplantation 90:1286-1293. https://doi.org/10.1097/TP.0b013e3182007bbf

Lechmann MD, Krooshoop J, Dudziak D et al (2001) The extracellular domain of CD83 inhibits dendritic cell-mediated T cell stimulation and binds to a ligand on dendritic cells. J Exp Med 194:18131821. https://doi.org/10.1084/jem.194.12.1813

Lechmann M, Zinser E, Golka A et al (2002) Role of CD83 in the immunomodulation of dendritic cells. Int Arch Allergy Immunol 129:113-118. https://doi.org/10.1159/000065883
Li H, Shi B (2015) Tolerogenic dendritic cells and their applications in transplantation. Cell Mol Immunol 12:24-30. https://doi.org/ 10.1016/j.smim.2011.06.007

Lutz MB (2012) Therapeutic potential of semi-mature dendritic cells for tolerance induction. Front Immunol 3:123. https://doi.org/10. 3389/fimmu.2012.00123

Lutz MB, Schuler G (2002) Immature, semi-mature and fully mature dendritic cells: which signals induce tolerance or immunity? Trends Immunol 23:445-449. https://doi.org/10.1016/S14714906(02)02281-0

Macedo C, Turquist H, Metes D et al (2012) Immunoregulatory properties of rapamycin-conditioned monocyte-derived dendritic cells and their role in transplantation. Transplant Res 1:1-7. https://doi. org/10.1186/2047-1440-1-16

Macedo C, Turnquist HR, Castillo-Rama M et al (2013) Rapamycin augments human DC IL-12p70 and IL-27 secretion to promote allogeneic type1 polarization modulated by NK cells. Am J Transplant 13:2322-2333. https://doi.org/10.1111/ajt.12351

Marín E, Cuturi MC, Moreau A (2016) Potential of tolerogenic dendritic cells in transplantation. Curr Transplant Rep 3:227-235. https://doi.org/10.1007/s40472-016-0109-6

Matsue H, Yang C, Matsue K et al (2002) Contrasting impacts of immunosuppressive agents (rapamycin, FK506, cyclosporin A, and dexamethasone) on bidirectional dendritic cell-T cell interaction during antigen presentation. J Immunol 169:3555-3564. https://doi.org/10.4049/jimmunol.169.7.3555

McDaniel DO, Zhou X, Moore CK et al (2010) Cardiac allograft rejection correlates with increased expressions of Toll-like receptors 2 and 4 and Allograft inflammatory factor 1. Transplant Proc 42:4235-4237. https://doi.org/10.1016/j.transproceed.2010.09. 091

Methe H, Zimmer E, Grimm C et al (2004) Evidence for a role of Tolllike receptor 4 in development of chronic allograft rejection after cardiac transplantation. Transplantation 78:1324-1331. https:// doi.org/10.1097/01.TP.0000137930.40597.03

Moini M, Schilsky ML, Tichy EM (2015) Review on immunosuppression in liver transplantation. World J Hepatol 7:1355-1368. https://doi.org/10.4254/wjh.v7.i10.1355

Monti P, Mercalli A, Leone BE et al (2003) Rapamycin impairs antigen uptake of human dendritic cells. Transplantation 75:137-145. https://doi.org/10.1097/00007890-200301150-00025

Moreau A, Alliot-Licht B, Cuturi MC et al (2017) Tolerogenic dendritic cell therapy in organ transplantation. Transpl Int 30:754764. https://doi.org/10.1111/tri.12889

Morelli AE, Thomson AW (2007) Tolerogenic dendritic cells and the quest for transplant tolerance. Nat Rev Immunol 7:610-621. https://doi.org/10.1038/nri2132

Naranjo-Gómez M, Raïch-Regué D, Oñate C et al (2011) Comparative study of clinical grade human tolerogenic dendritic cells. J Transl Med 9:89. https://doi.org/10.1186/1479-5876-9-89

Ochando J, Ordikhani F, Jordan S et al (2020) Tolerogenic dendritic cells in organ transplantation. Transpl Int 33:113-127. https://doi. org/10.1111/tri.13504

Ohtani M, Nagai S, Kondo S et al (2008) Mammalian target of rapamycin and glycogen synthase kinase 3 differentially regulate lipopolysaccharide-induced interleukin-12 production in dendritic cells. Blood 112:635-644. https://doi.org/10.1182/ blood-2008-02-137430

Pino-Lagos K, Michea P, Sauma D et al (2010) Cyclosporin A-treated dendritic cells may affect the outcome of proliferation. Biol Res $1: 333-337$

Pletinckx K, Döhler A, Pavlovic V et al (2011) Role of dendritic cell maturity/costimulation for generation, homeostasis, and suppressive activity of regulatory T cells. Front Immunol 2:39. https:// doi.org/10.3389/fimmu.2011.00039 
Prechtel AT, Steinkasserer A (2007) CD83: an update on functions and prospects of the maturation marker of dendritic cells. Arch Dermatol Res 299:59-69. https://doi.org/10.1007/s00403-007-0743-z

Que W, Guo WZ, Li XK (2020) Manipulation of regulatory dendritic cells for induction transplantation tolerance. Front Immunol 11:582658. https://doi.org/10.3389/fimmu.2020.582658

Rosborough BR, Raïch-Regué D, Matta BM et al (2013) Murine dendritic cell rapamycin-resistant and rictor-independent MTOR controls IL-10, B7-H1, and regulatory T-cell induction. Blood 121:3619-3630. https://doi.org/10.1182/blood-2012-08-448290

Sanjana P, Devi K, Anandasabapathy N (2017) The origin of DCs and capacity for immunologic tolerance in central and peripheral tissues. Semin Immunopathol 39:137-152. https://doi.org/10.1007/ s00281-016-0602-0

Sansom DM, Walker LSK (2006) The role of CD28 and cytotoxic T-lymphocyte antigen-4 (CTLA-4) in regulatory T-cell biology. Immunol Rev 212:131-148. https://doi.org/10.1111/j.0105-2896. 2006.00419.x

Sauma D, Fierro A, Mora JR et al (2003) Cyclosporine preconditions dendritic cells during differentiation and reduces IL-2 and IL-12 production following activation: a potential tolerogenic effect. Transplant Proc 35:2515-2517. https://doi.org/10.1016/j.trans proceed.2003.09.020

Sordi V, Bianchi G, Buracchi C et al (2006) Differential effects of immunosuppressive drugs on chemokine receptor CCR7 in human monocyte-derived dendritic cells: selective upregulation by rapamycin. Transplantation 82:826-834. https://doi.org/10.1097/01.tp. $0000235433.03554 .4 \mathrm{f}$

Stallone G, Infante B, Di Lorenzo A et al (2016) MTOR inhibitors effects on regulatory $\mathrm{T}$ cells and on dendritic cells. J Transl Med 14:152. https://doi.org/10.1186/s12967-016-0916-7

Steinman RM, Hawiger D, Nussenzweig MC (2003) Tolerogenic dendritic cells. Annu Rev Immunol 21:685-711. https://doi.org/10. 1146/annurev.immunol.21.120601.141040

Stenger EO, Rosborough BR, Mathews LR et al (2014) IL-12hi rapamycin-conditioned dendritic cells mediate IFN- $\gamma$-dependent apoptosis of alloreactive $\mathrm{CD} 4+\mathrm{T}$ cells in vitro and reduce lethal graftversus-host disease. Biol Blood Marrow Transplant 20:192-201. https://doi.org/10.1016/j.bbmt.2013.11.007

Sumpter TL, Thomson AW (2011) The STATus of PD-L1 (B7-H1) on tolerogenic APCs. Eur J Immunol 41:286-290. https://doi.org/10. 1002/eji.201041353

Svajger U, Rozman P (2014) Tolerogenic dendritic cells: molecular and cellular mechanisms in transplantation. J Leukoc Biol 95:53-69. https://doi.org/10.1189/jlb.0613336

Švajger U, Rožman PJ (2020) Recent discoveries in dendritic cell tolerance-inducing pharmacological molecules. Int Immunopharmacol 81:106275. https://doi.org/10.1016/j.intimp.2020.106275

Szabo G, Gavala C, Mandrekar P (2001) Tacrolimus and cyclosporine A inhibit allostimulatory capacity and cytokine production of human myeloid dendritic cells. J Investig Med 49:442-449. http:// jim.bmj.com/content/49/5/442

Tajima K, Amakawa R, Ito T et al (2003) Immunomodulatory effects of cyclosporin A on human peripheral blood dendritic cell subsets. Immunology 108:321-328

Taner T, Hackstein H, Wang Z et al (2005) Rapamycin-treated, alloantigen-pulsed host dendritic cells induce Ag-specific T cell regulation and prolong graft survival. Am J Transplant 5:228-236. https://doi.org/10.1046/j.1600-6143.2004.00673.x

Testro AG, Visvanathan K, Skinner N et al (2011) Acute allograft rejection in human liver transplant recipients is associated with signaling through Toll-like receptor 4. J Gastroenterol Hepatol 26:155-163. https://doi.org/10.1111/j.1440-1746.2010.06324.x

Thomson AW, Ezzelarab MB (2018) Regulatory dendritic cells: profiling, targeting, and therapeutic application. Curr Opin Organ Transplant 23:538-545. https://doi.org/10.1097/MOT.00000 00000000565

Thomson AW, Metes DM, Ezzelarab MB et al (2019) Regulatory dendritic cells for human organ transplantation. Transplant Rev 33:130-136. https://doi.org/10.1016/j.trre.2019.05.001

Turnquist HR, Raimondi G, Zahorchak AF et al (2007) Rapamycinconditioned dendritic cells are poor stimulators of allogeneic CD4+ T cells, but enrich for antigen-specific Foxp3+ T regulatory cells and promote organ transplant tolerance. J Immunol 178:7018-7031. https://doi.org/10.4049/jimmunol.178.11.7018

Turnquist HR, Cardinal J, Macedo C et al (2010) MTOR and GSK-3 shape the CD4+T-cell stimulatory and differentiation capacity of myeloid DCs after exposure to LPS. Blood 115:4758-4769. https://doi.org/10.1182/blood-2009-10-251488

Wang GY, Chen GH, Li H et al (2009) Rapamycin-treated mature dendritic cells have a unique cytokine secretion profile and impaired allostimulatory capacity. Transpl Int 22:1005-1016. https://doi. org/10.1111/j.1432-2277.2009.00901.x

Wolfle SJ, Strebovsky J, Bartz H et al (2011) PD-L1 expression on tolerogenic APCs is controlled by STAT-3. Eur J Immunol 41:413-424. https://doi.org/10.1002/eji.201040979

Woltman AM, de Fijter JW, Kamerling SW et al (2000) The effect of calcineurin inhibitors and corticosteroids on the differentiation of human dendritic cells. Eur J Immunol 30:1807-1812. https:// doi.org/10.1002/1521-4141(200007)30:7\%3c1807::AID-IMMU1 807\%3e3.0.CO;2-N

Woltman AM, De Fijter JW, Kamerling SWA et al (2001) Rapamycin induces apoptosis in monocyte- and CD34-derived dendritic cells but not in monocytes and macrophages. Blood 98:174-180. https://doi.org/10.1182/blood.V98.1.174

Xu JF, Huang BJ, Yin H et al (2007) A limited course of soluble CD83 delays acute cellular rejection of MHC-mismatched mouse skin allografts. Transpl Int 20:266-276. https://doi.org/10.1111/j.14322277.2006.00426.x

Yamada A, Kishimoto K, Dong VM et al (2001) CD28-independent costimulation of $\mathrm{T}$ cells in alloimmune responses. J Immunol 167:140-146. https://doi.org/10.4049/jimmunol.167.1.140

Yang Y, Xin Z, Chu J et al (2015) Involvement of caveolin-1 in CD83 Internalization in mouse dendritic cells. Cell Transplant 24:13951404. https://doi.org/10.3727/096368914X682116

Zheng Y, Manzotti CN, Liu M et al (2004) CD86 and CD80 differentially modulate the suppressive function of human regulatory $\mathrm{T}$ cells. J Immunol 172:2778-2784. https://doi.org/10.4049/jimmu nol.172.5.2778

Publisher's Note Springer Nature remains neutral with regard to jurisdictional claims in published maps and institutional affiliations. 